\title{
Purposeful Field Trip: Impact on Experiential Learning Opportunities and Critical Thinking Skills
}

\author{
Su Chern Foo ${ }^{1,2 *}$ and Kien Kheng $\mathbf{F o o}^{3}$ \\ ${ }^{1}$ School of Science, Monash University Malaysia, Jalan Lagoon Selatan, 47500, Selangor Darul Ehsan, \\ Malaysia \\ ${ }^{2}$ Tropical Medicine and Biology Multidisciplinary Platform, 47500 Selangor Darul Ehsan, Malaysia \\ ${ }^{3}$ Sparks Education PLT, 51200, Kuala Lumpur, Malaysia
}

\begin{abstract}
While Bloom's taxonomy is a well-established learning hierarchy, higher-order thinking skills (HOTS), defined as the three upper levels, are seldom attained due to traditional teaching practices and time constraints of units or subjects. Therefore, adopting innovative pedagogy models like experiential learning provides opportunities for the demonstration and development of HOTS. The study's objective shows that field trips are crucial components of experiential learning, and when designed with a purpose, promote higher-order thinking skills. This study used a descriptive design, specifically videos, to collect qualitative data for small sample sizes followed by a structured questionnaire consisting of closed questions. All videos were transcribed, and thematic analyses were used. The quantitative data were analysed descriptively, and data were presented using frequency distribution. It was found that this field trip assessment design enabled the skills demonstration spanning Bloom's learning spectrum. Furthermore, HOTS were used more frequently than basic thinking skills. A quantitative survey on student perceptions revealed that pre-trip activities are equally important as during-trip activities. Findings from this exploratory study provide insights for future education-related research in the field of HOTS, transferable skills, and values.
\end{abstract}

ARTICLE INFO

Article history:

Received: 16 June 2021

Accepted: 08 October 2021

Published: 18 February 2022

DOI: https://doi.org/10.47836/pjssh.30.1.01

$\overline{\text { E-mail addresses: }}$

foo.suchern@monash.edu, suchern@gmail.com (Su Chern Foo) kienkheng@yahoo.com (Kien Kheng Foo)

* Corresponding author
Keywords: Active learning, creation, experiential learning, field trip design, higher-order thinking skills, transferable skills

\section{INTRODUCTION}

Higher-order thinking skills or HOTS are defined as the three upper levels of Bloom's revised taxonomy, i.e., analysis, evaluation, and creation (Anderson \& Krathwohl, 2001; 
Essig et al., 2018). HOTS verbs commonly include design, develop, propose, construct, plan, solve. While educators acknowledge the importance of HOTS, the challenge of effectively conducting HOTS activities within a limited timeframe (Ganapathy et al., 2017) and traditional linear learning and teaching concepts (Zohar et al., 2001) discourages implementation. It is a common problem faced in education institutions wherein teaching and learning pedagogies in an exam-based education system result in the emphasis of fact memorisation instead of thinking skills (Jones, 2010; Mustaffa, 2007). HOTS can be observed in some field trip units (Hurley, 2006; Kuchel et al., 2015), but most traditional fieldwork designs engage only basic levels of thinking, i.e., knowledge, comprehension, and application. While these are irrefutably important components for cognitive thinking, learning seldom goes beyond the cognitive spectrum's basic levels. Indeed, HOTS are more difficult to learn or teach but more valuable and practical because these skills are highly likely to be used in the workplace. Teaching activities that promote HOTS include field trips, creating an environment for idea exploration and prompting students to make a hypothesis, problem-solving, engaging students in oral presentations, asking students to reflect on their experiences or encouraging students to reflect on how content is related to world issues. Among these, field trips are an important component of experiential learning and have shown to be successful in promoting HOTS. For example, Peasland et al. (2019) found that fieldwork in environmental science enabled opportunities for students to develop employer-desirable technical skills, e.g., identifying organisms, describing soil profiles, and transferable skills, e.g., problem-solving, critical thinking, adapting to new situations.

Experiential learning or "learning-bydoing" is the process of knowledge creation through transformative experiences where knowledge results from the combination of grasping and transforming knowledge (Kolb $\&$ Kolb, 2009). The 4 phases of experiential learning are design, conduct, evaluation and feedback (Wolfe \& Byrne, 1975). Transformative learning experiences come in experiential learning opportunities from classrooms, laboratory practicals, field trips (Scarce, 1997), internships and employment (Huisman et al., 2019), knowledge transfer workshops in academia and industry and personal development training for lifelong learning. Experiential learning is a timely and modern educational theory (Sharlanova, 2004) and is increasingly becoming a major component of teaching delivery in schools and universities to promote science education (Oliver et al., 2018), environment studies (Jose et al., 2017) and even culture awareness (Dabamona \& Cater, 2018). The value provided by experiential learning is that it facilitates the individual's integrated development of the affective, perceptual, cognitive, and behavioural domains (Passarelli, 2016). For example, Boyle et al. (2007) showed that field trips directly engage students with intense and immersive experiences by activating affective and cognitive domains. 
Educators designed field trips with an educational goal in mind (Kuchel et al., 2015; Peasland et al., 2019). These goals can vary but mostly include enforcing classroom learning, promoting applications, encouraging group interaction, deepening conceptual development, and stimulating appreciation for the environment (Lei, 2010). It is where our research comes in. The design of purposeful "pre-trip," "during-trip," and "post-trip" learning activities aligned to the learning outcomes of the unit will determine the effectiveness of teaching and learning. The traditional field trip design in undergraduate biology courses used expository learning design activities, which included activities like "show and tell" and simple observations (Domin, 1999). It is comparable to in-house, recipe-style laboratory practical, with the disadvantage of limiting student learning with instructional approaches. Students are often left alone to contextualise what they have done in the lab to its relevance in daily life. When unable to connect the dots, such instructional approaches can severely limit student motivations. Besides, traditional field trip activities tend to engage lower cognitive levels of learning like recalling information and understanding. It results in the preclusion of higher cognitive thinking like analysis, evaluation, and creation.

Field trips are an important component of experiential learning, and when designed with a purpose, could promote higher-order thinking skills. This study describes a purposeful field trip design of an experiential learning trip, with a focus on (1) identifying HOTS skills exhibited during the three stages (pre, during, post) of the field trip activities and (2) mapping these demonstrated skills according to Bloom's revised taxonomy. This study is aligned to the Malaysian Education Blueprint 2015-2025, National Higher Education Action Plan (NHEAP) and current worldwide science education reforms to facilitate the development of HOTS in students via purposeful experiential learning opportunities. Furthermore, the study adds value to the existing body of knowledge in the last ten years by showing how a field trip design stimulates the demonstration of HOTS among third-year undergraduates. Our findings may focus on higher education but can benefit instructors of a wider range of educational levels by being one of the few targeted experiential learning research projects conducted in a tropical biodiversity hotspot. This paper investigates how purposefully designed field trips can promote higher-order thinking skills. The impact of this study is two-fold and achieved by firstly, collating video data that evidences the demonstration of HOTS during the field trip. In addition, it also aims to measure student perception of their learning experiences post field trip.

\section{MATERIALS AND METHODS}

\section{Ethics Approval}

This study was approved by the Human Research Ethics Committee reference number: 22574. 


\section{Field Trip Design}

Third-year BSc tropical environmental biology students participated in a field trip at Lang Tengah, a tropical island in Kuala Terengganu, Malaysia, for four days three nights (22 ${ }^{\text {nd }}$ April 2019-25 $5^{\text {th }}$ April 2019). The selection of Lang Tengah Island, an island off the East Coast of Malaysia, as a field site and its' timing, was to capitalise on the intact tropical corals located in marine parks as well as a rare opportunity to observe sea turtle landings. Students consisted of 15 Malaysians and three international students (two Australians and 1 British). The gender ratio of the respondents was fairly distributed, i.e., ten females and eight males with an age range from 20 to 23 years old. Thirteen students were from tropical environmental biology, three from biotechnology, one from medical bioscience and one from food science and technology. Figure 1 illustrates this field trip designed according to Wolfe and Byrne (1975), while Table 1 details the learning activities and assessments selected to meet the intended learning outcomes of the field trip.

Pre-Trip. Prior to this study, a preliminary survey was carried out to collect data on student perception regarding the participation in field trips in April 2018. No fieldwork projects and only observational studies were carried out for that year. In the open-ended survey question on "identified gaps and room for improvement," students suggested to "include field experiments that could be done" and "perhaps in the future the group presentations could be made into one, class-wide, presentation, which include videos, PowerPoint slides etc." This valuable student feedback in 2018 formed the basis for a purposeful field trip design in 2019. The main intent of this new field trip design was to provide experiential learning opportunities for students to acquire and utilise higher-order thinking throughout the three stages of the design.

In the lecture series that led up to the field trip, students learn about water characteristics and how it supports life in the freshwater and marine ecosystems, coastal landforms and coral reefs, various groups of aquatic organisms (from phytoplankton, zooplankton, aquatic plants, insects, amphibians, reptilians, birds, and mammals). They followed an instructorled field trip outlined in a field manual to learn about phytoplankton and water sampling techniques early in the semester. The subsequent laboratory sessions made microscopic observations, identification, enumeration, and taxonomic classification of the collected phytoplankton. These pretrip learning activities were intended to prepare students and develop skills relevant to the fieldwork proposal assessment. The fieldwork proposal assessment requires the student to work in teams to design and propose a field project. They then receive feedback on the fieldwork proposal from the lecturer and invited experts through the inquiry approach to provide better clarity and understanding of their respective projects prior to the days leading up to the field trip itself. This field trip design followed the recommendation by Orion (1993) and Wolfe and Byrne (1975) on good practices in field 
trip design for learning. In addition, safety was a priority as it was a high-risk field trip activity. Risk management strategies included a staff: student ratio of 1:4 and implementing a buddy system. Moreover, all staff joining the field trip were first aid trained, and a certified diver joined all snorkelling trips. Prior to the field trip, students also underwent a water confidence test and compulsory safety briefing. It is worthy to note that during the journey to the field site itself, students were introduced to a wide range of life skills. These skills included completing a risk assessment and emergency contact forms, preparing and packing sampling equipment and working in areas with little or no internet access.

During-Trip. As an integral part of the unit, the field trip took place early in the learning sequence, i.e., mid-semester, to close the student-instructor feedback loop. On the first day of the trip, students were safety-briefed by a local guide. Also, a walking tour around the island was done to survey suitable project sites for conducting each fieldwork project. In the following days between project execution timings, students joined sea turtle and coral biology conservation talks conducted by conservationists from a local NGO. At night, all students participated in the night walk to observe sea turtle landings. For each field trip project, the detailed methodology explained by each group can be found in Appendix 1 (Supplementary materials). On the last day of the field trip, students participated in a beach clean-up activity.
Post-Trip. Post field trips, students participated in a debriefing activity to encourage reflection on their learnings. It included presenting study findings and sharing new personal experiences and insights gained. Students did so by reporting study findings in the form of 6-minute videos. Video transcriptions can be accessed in Appendix 2 (Supplementary materials). Post transcription, thematic analysis, and mapping identified skills to learning outcomes were tabulated in Table 1. In addition, a survey was conducted to gain student perception about the field trip. The instructor also completed a selfevaluation exercise to improve future field trips continuously.

\section{Data Collection}

Descriptive design, a qualitative approach to assess the skills gained by students during fieldwork, were collected from four group videos, each lasting approximately six minutes. All video data were transcribed, and thematic analyses were used in accordance with past studies (Heath et al., 2010; Nowell et al., 2017; Saldaña, 2015). Coding is an iterative process, i.e., when a new code emerges from data, previously coded transcripts are revisited to check coding accuracy, and new codes are applied as appropriate. Once coding was completed, the codes were organised into main and subthemes. It is worthy to note that the main author is also the instructor for this unit and therefore acknowledges the positionality influence on study findings. In order to reduce bias, this process was repeated 
between an independent transcriber and co-authors.

Quantitative data collection consisted of a structured questionnaire. It was aimed at evaluating student perceptions about their learning experiences. A series of closed questions $(n=9)$ were distributed to all students involved. The survey asked respondents to rate their learning experiences at Lang Tengah captured in a 5-point Likert scale (one-strongly disagree; five-strongly agree). The quantitative data were analysed descriptively, and data were presented using frequency distribution.

\section{RESULTS}

\section{Learning Outcomes, Assessments, Field Trip Stages and Evidential Learning Skills}

From the qualitative data, four themes and ten sub-themes emerged from the transcribed data in the videos. The themes are (1) cognitive skills in Bloom's revised taxonomy, (2) transferable skills, (3) values and (4) others. Among the ten sub-themes identified $(n=146)$, cognitive skills were the most recounted skills by the students $(n=101)$. It was followed by transferable knowledge $(n=24)$, values $(n=13)$, and others $(n=8)$ (Figure 2). Overall, pre-trip activities represented a combination of both student-led and instructor-led tasks. These tasks motivate the students by providing learning-by-doing or experiential learning opportunities for all the cognitive skills ascribed to Bloom's revised taxonomy. At the same time, students hone transferable skills, environmental values while having fun, which could not have happened without these experiential learning opportunities. Detailed evidence mapped to the cognitive skills are shown in Table 1.

The updated Bloom's classification of cognitive skills ranks from level 1 to level 6 , starting with knowledge, comprehension, application, analysis, evaluation, and ending with the creation spectrum (Anderson \& Bloom, 2001). Interestingly, HOTS, i.e., the three upper levels of Bloom's revised taxonomy, were found to be in a higher frequency $(n=57)$ as compared to the three lower levels $(n=44)$. Specifically, the cognitive evaluation skills were the most demonstrated ( $n=28$ ), while the rest of the cognitive skills were approximately the same. Meanwhile, equally important findings like transferable skills (i.e., collaboration within a team, technologically prepared), values (i.e., environmental awareness), and others (learning while having fun) are noted in the analysis. It was also noted that students exhibited teamwork $(n=13)$, ICT $(n=11)$, environmental sustainability awareness $(n=13)$, and learning while having fun $(n=8)$.

\section{STUDENT PERCEPTION ANALYSIS}

Feedback was collected from 14 out of 18 students (78\% response rate) with survey questions related to the pre-trip, during-trip and post-trip activities. Overall, it was found that more than $50 \%$ of students agreed or strongly agreed to all nine survey questions (Figure 3 ). In pre-trip activities, more than $90 \%$ of respondents agreed that "the organisation and progression of the field 
Field Trip Design to Promote Critical Thinking Skills

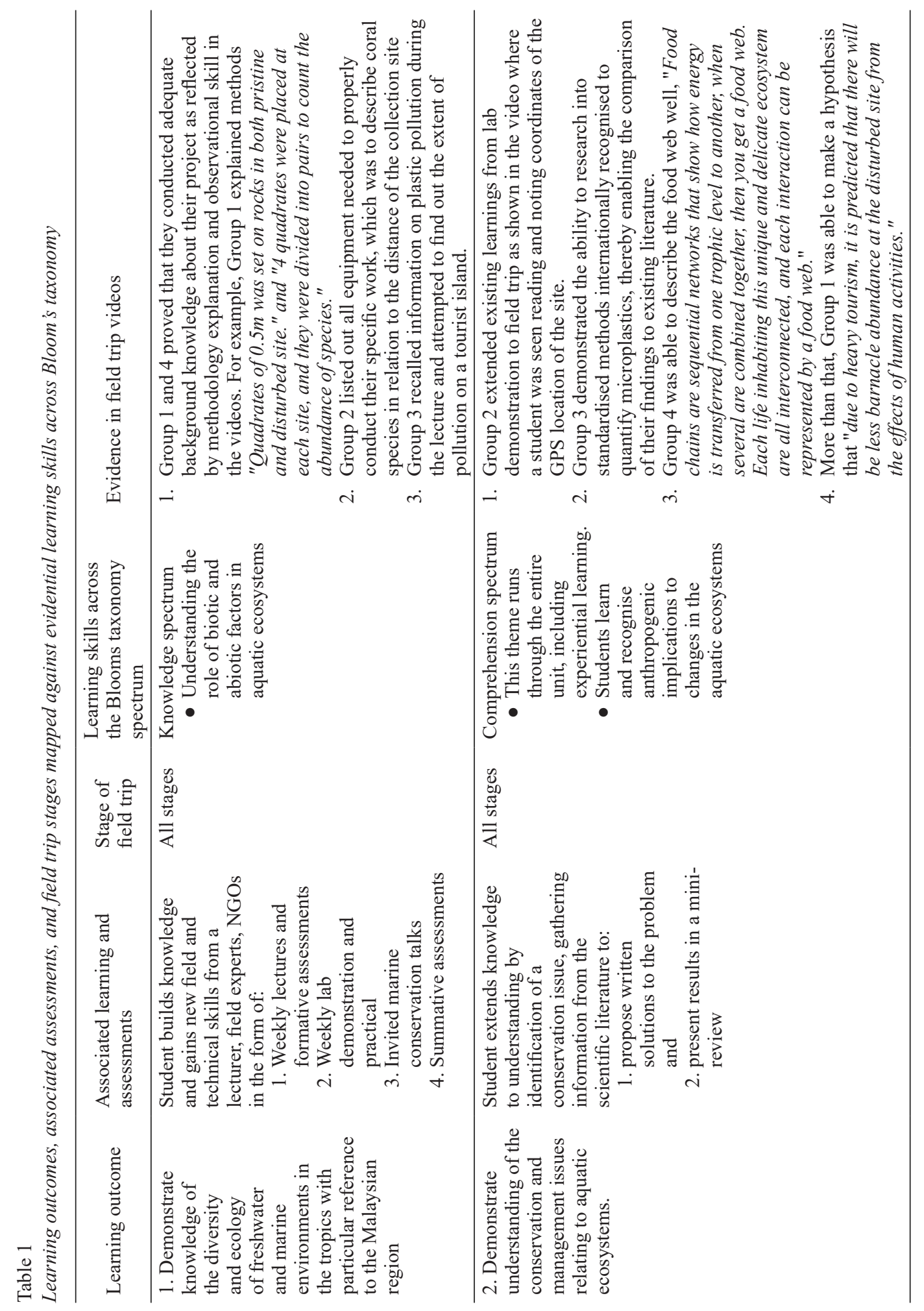




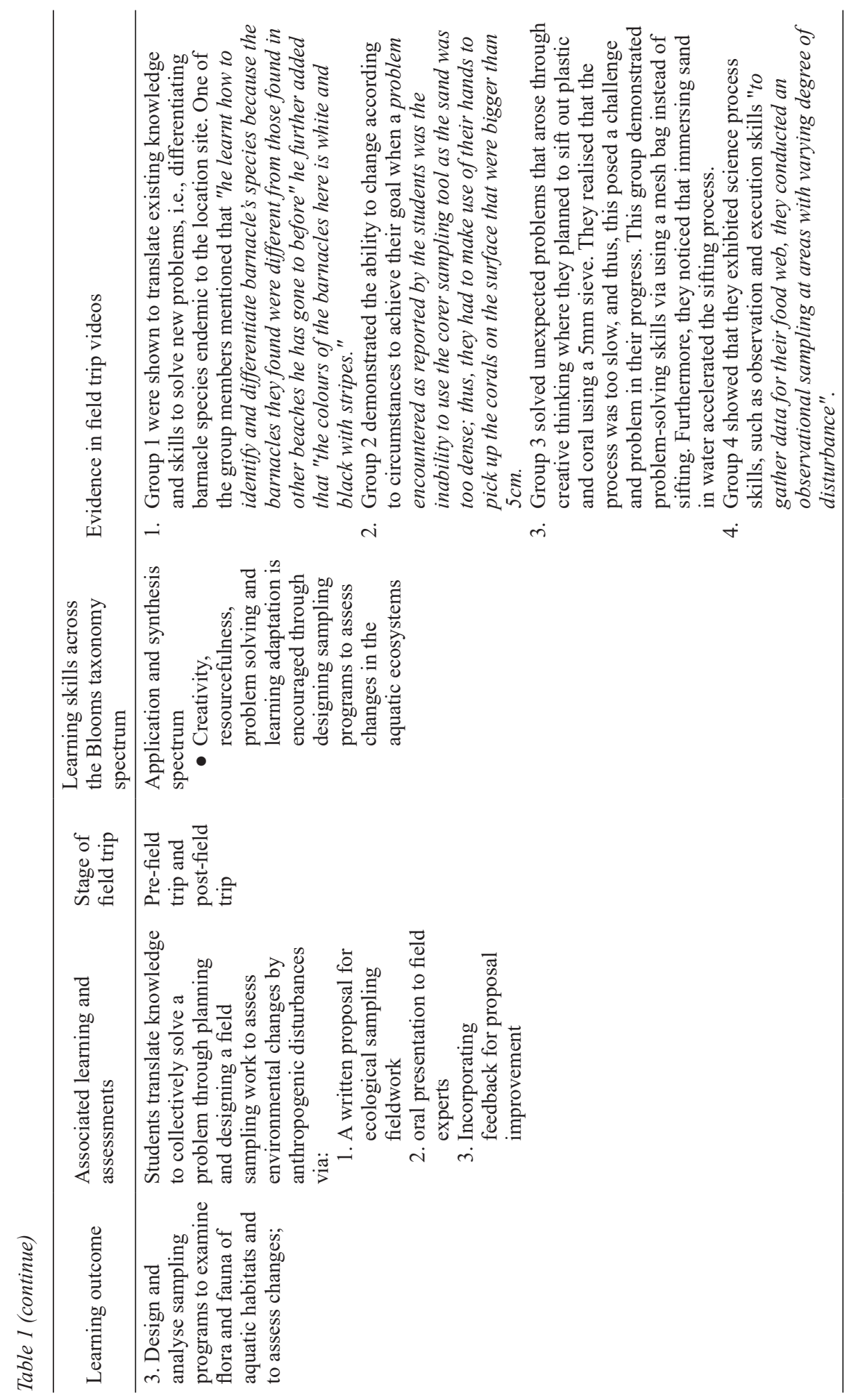




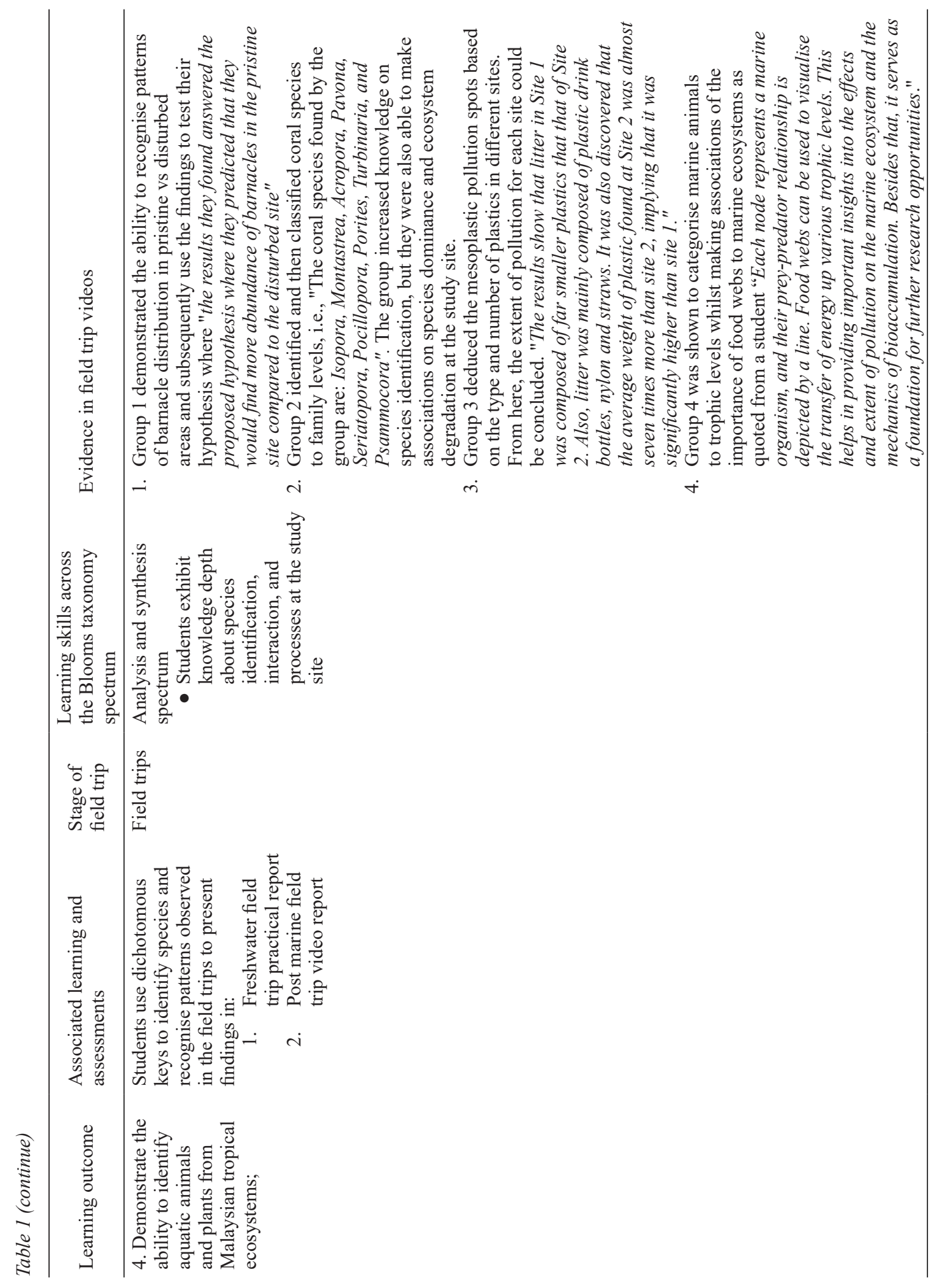




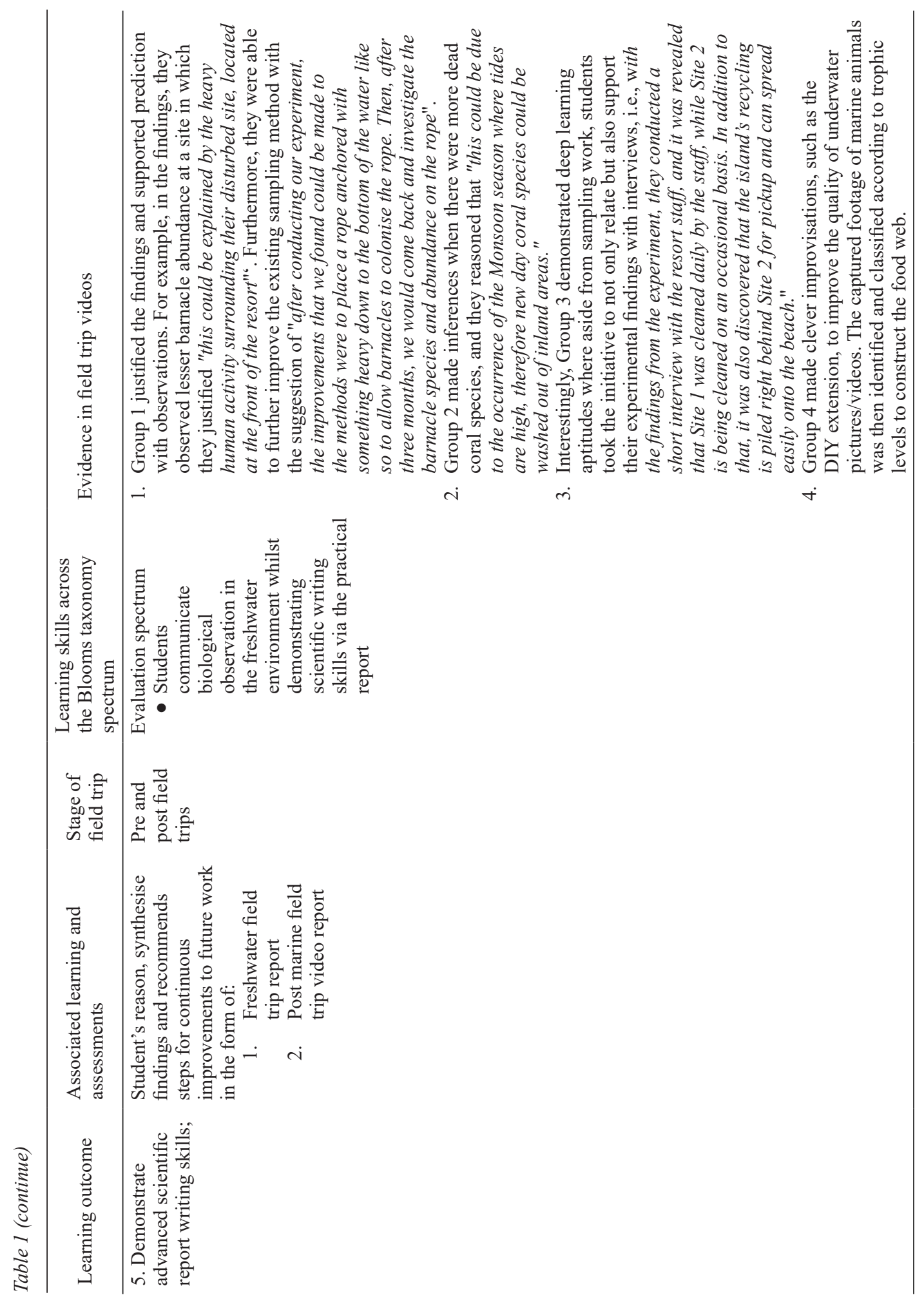


Field Trip Design to Promote Critical Thinking Skills

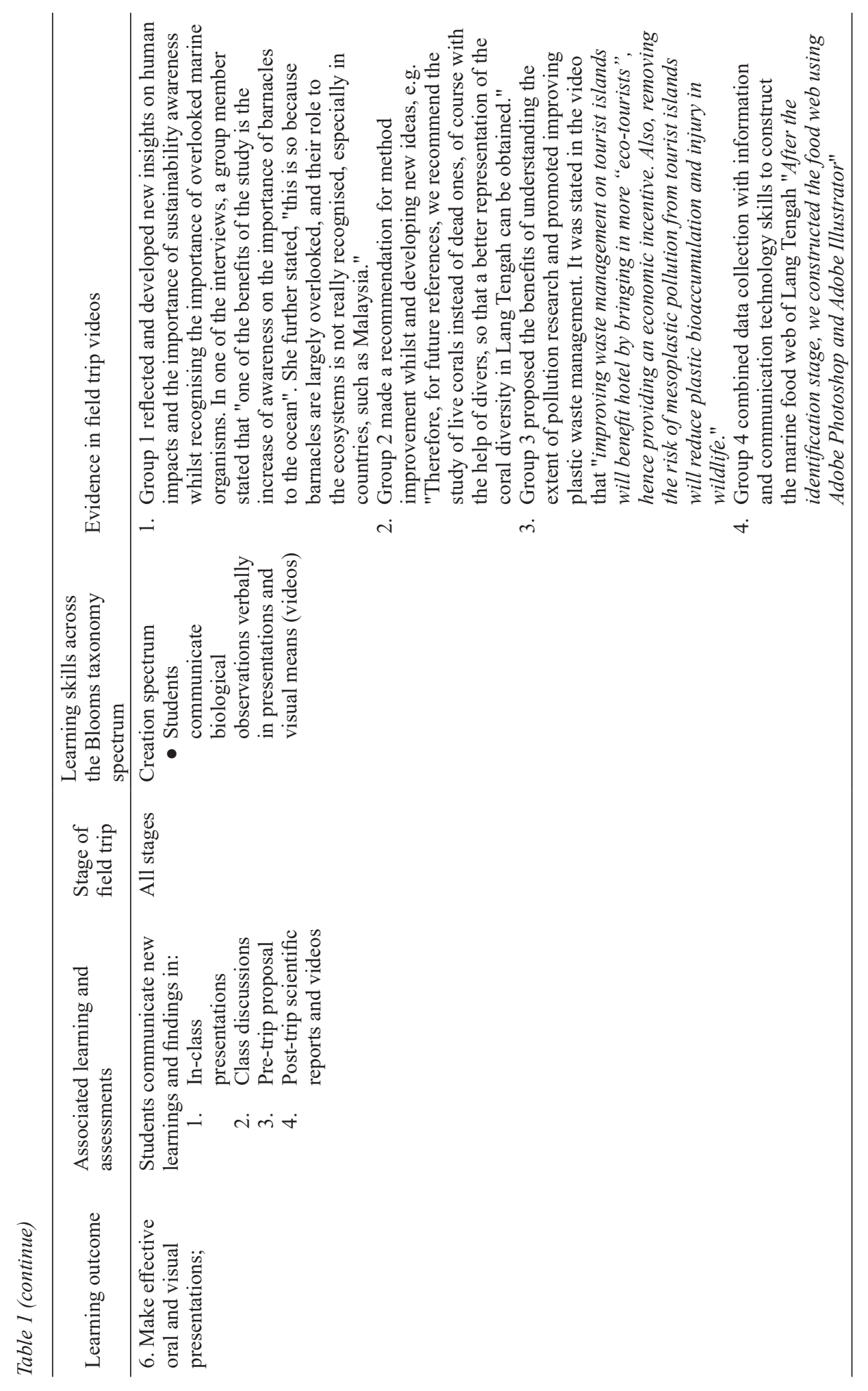


trip were sensible and coherent". Further to this, $79 \%$ of respondents strongly agreed that "pre-trip preparation work enriched the learning experience." Secondly, 85\% of respondents strongly agreed with survey question no. 4 that "individual assistance and guidance during the trip (face-to face) was available when needed". Also, all respondents unanimously agreed that "the learning resources provided during the trip supported their learning needs". Finally, more than $85 \%$ of the respondents agreed or strongly agreed that "the field experience was useful and intellectually stimulating". It led to the achievement of the learning outcomes of the unit as reflected by survey question number eight on "overall satisfaction of the field trip". As a result, more than $79 \%$ of respondents strongly recommended juniors to enrol in the unit in the future (survey question no.9).

\section{DISCUSSION}

\section{Students Demonstrated All Cognitive Skills Across Bloom's Revised Taxonomy}

Field trips provide unique learning environments that present different and challenging learning opportunities like the workplace. While maximising the potential of the selected marine site, the field trip design consisting of pre-trip, during-trip, and post-trip components were central to providing experiential learning opportunities while enforcing learnings from lectures. Table 1 describes the learning outcomes, associated learning tasks, and their educational underpinnings mapped against the evidential learning skills across Bloom's taxonomy. At the same time, the table also shows learning progression through the different field trip stages.

\section{A Field Trip Design That Promotes HOTS}

Higher-order thinking skills is a highly sought-after employment skill set. Kenayathulla et al. (2019) stated that aside from being able to work independently, proactive and able to perform under pressure, employers look for soft skills, e.g., managing resources, good communication and interpersonal skills, team-playing, and HOTS like reasoning, problem-solving, and decision making (Shafie \& Nayan, 2010). For instance, the field trip activities listed in Table 1 had groups complete their task within a limited timeframe and resource availability, providing students with learning opportunities to hone HOTS. In addition, the design of assessment tasks across pre-trip, during trip and post trip enabled the demonstration of all six cognitive processes. Unlike in house, recipe-style laboratory experiments, this field trip design mimicked the workplace environment by providing experiential learning opportunities (Figure 1). Detailed planning, decision making, creative thinking and cohesive communication were important to reach the final goal.

Besides that, a past study by Hurley (2006) found that the higher cognitive levels of analysis, synthesis, and evaluation were achieved when the field trip ended. However, this was not the case in this study. During the field trip, not only did students 


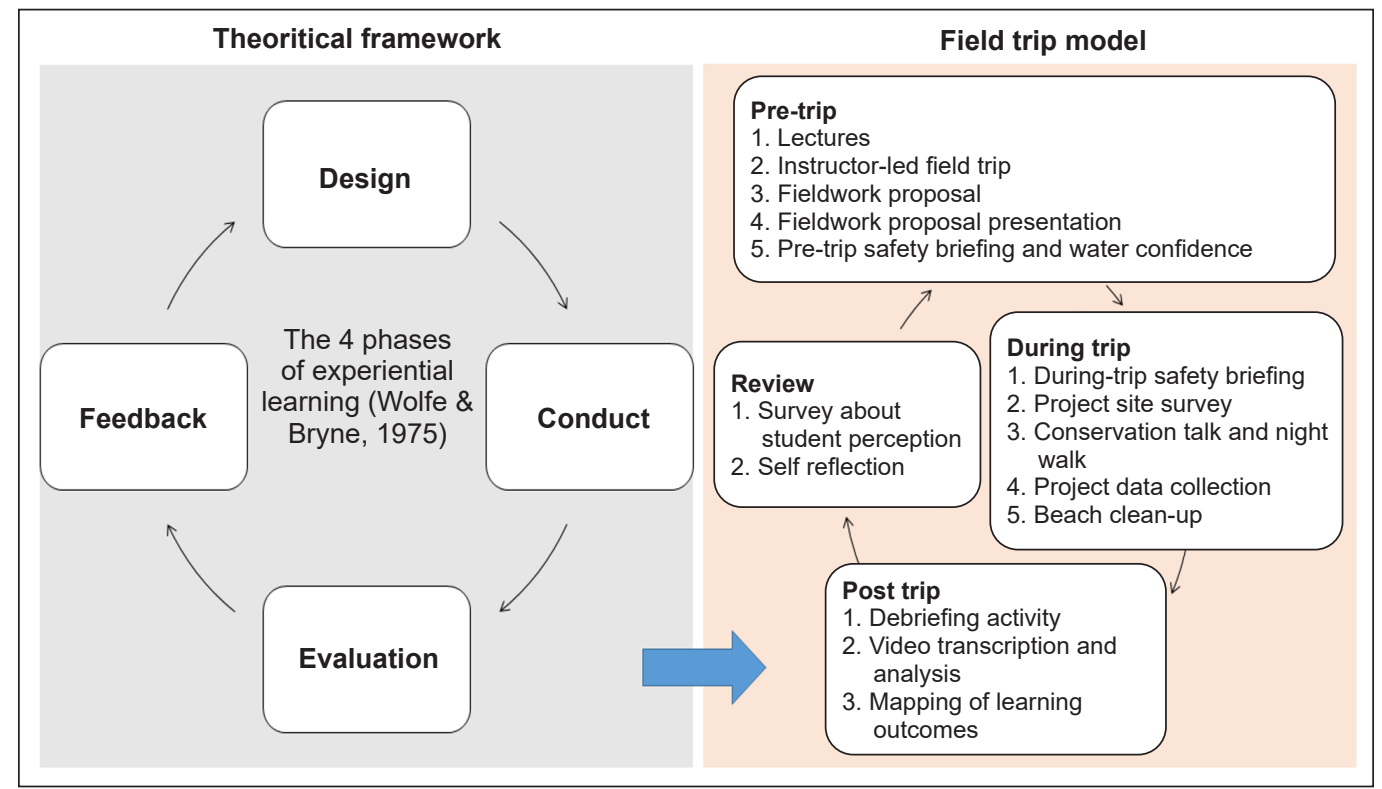

Figure 1. Theoretical framework and field trip model in this study

demonstrate learning skills across Bloom's revised taxonomy, but the frequency of students also demonstrating HOTS (i.e., analysis, evaluation, and creation) were higher ( $\mathrm{n}=57)$, compared to basic learning skills (i.e., knowledge, comprehension and application) of $n=44$ (Figure 2). In the analysis spectrum, it was observed that students demonstrated skills in species identification, classification, enumeration and recognising patterns in collected data subsequently presented in the form of tables and figures. For example, Group 1 formed a hypothesis in their field trip proposal as part of pre-trip learning activities. During the trip, they demonstrated the ability to recognise patterns of barnacle distribution in pristine vs disturbed areas, and findings were then used to answer the initial postulation. In the evaluation learning spectrum, students demonstrated skills in justifying findings, supporting findings with evidence, comparing and reflecting on whether the findings were consistent with their prior knowledge, and finally drawing conclusions. It is evident when Group 1 justified new findings and supported prediction with site observations. They explained that there was lesser barnacle abundance at a site in which they further justified "this could be explained by heavy human activity surrounding their disturbed site, located at the front of the resort".

In the creation spectrum, the field trip enabled experiential learning opportunities for students to make future recommendations to improve their respective projects. For example, it was suggested by group 1 that, "after conducting our experiment, the improvements that we found could be made to the methods were to place a rope anchored with something heavy down to the bottom of the water like so to allow barnacles to colonise the rope. Then, 


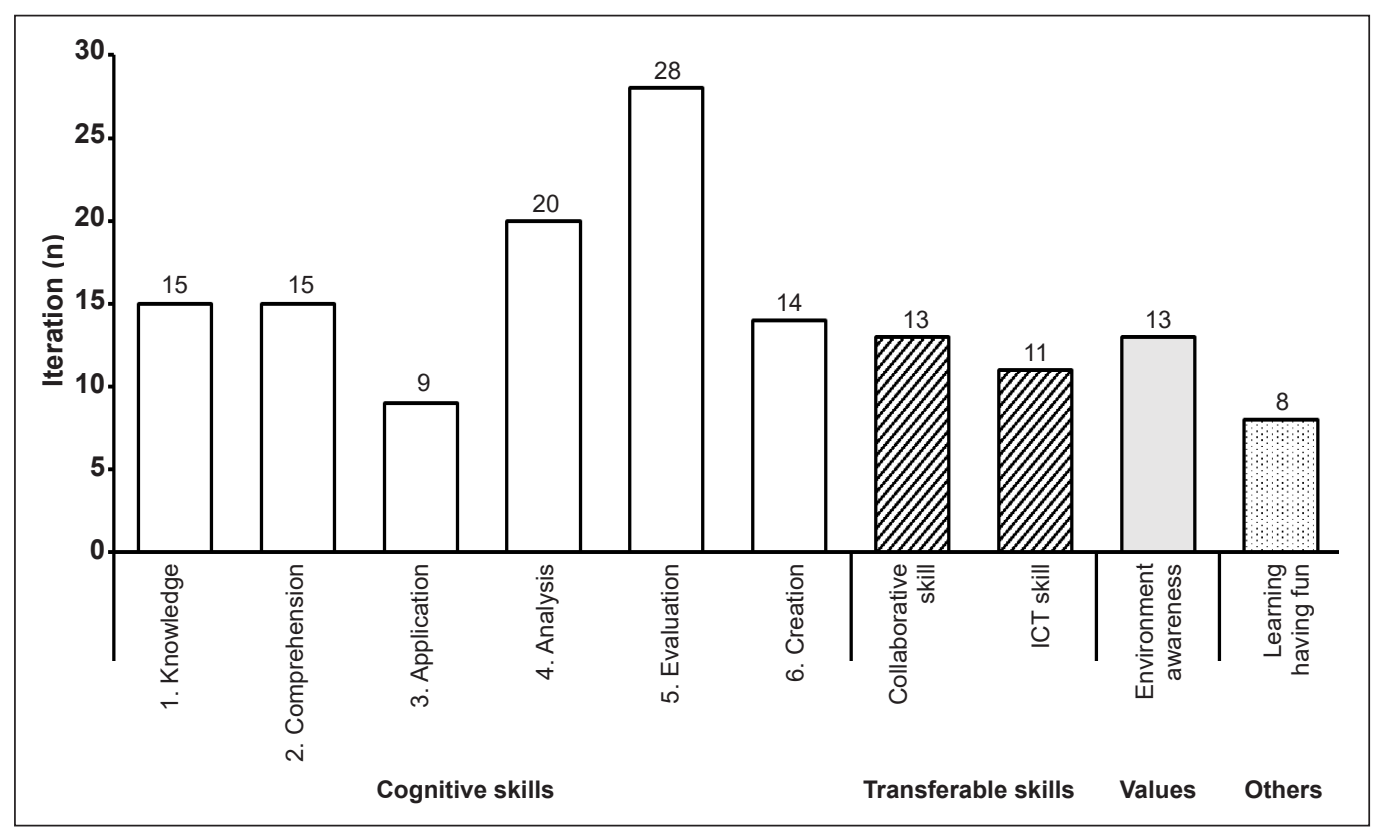

Figure 2. Frequency distribution of Bloom's taxonomy of cognitive skills, transferable skills, values, and others

after three months, we would come back and investigate the barnacle species and abundance on the rope. "Furthermore, they recognised the importance of overlooked marine organisms. Student A stated that "one of the benefits of the study is the increase of awareness on the importance of barnacles to the ocean." She further stated, "This is because barnacles are largely overlooked and their role to the ecosystems is not really recognised, especially in countries, such as Malaysia."

Moreover, this study found that specific skills in the evaluation spectrum were the most used among the three HOTS. These skills included evaluating, reasoning, justifying, predicting, solving, combining, verifying, and improvising. In the field, changing circumstances like weather, tidal timings, physical boulders, or restricted areas compel students to use skills not usually applied in the laboratory environment. It includes a combination of HOTS and transferable skills, i.e., adapting to current circumstances, problem-solving and good time management. This type of first-hand environmental study is a prime example of an experiential learning opportunity that promotes quick thinking and collaborative decision making to achieve a common goal. For example, adapting and problem-solving skills were required from both Group 2 and 3. Group 2 faced the challenge of using the sand corer due to dense sandy beach as mentioned by student B: 'Unfortunately, we were unable to use the sand corer as the sand was too dense at lower elevation level. Thus, the alternative was to select corals on the surface that were bigger than $5 \mathrm{~cm}$.' Another good example concerns the sand 
sifting process for mesoplastics previously planned in Group 3, where it was too slow. It was how student $\mathrm{C}$ described it: 'Excavate top $5 \mathrm{~cm}$ of sand from the quadrat and sift out plastic and coral using a $5 \mathrm{~mm}$ sieve was too slow. Instead, fill up a mesh bag with the quadrat's sand and immerse the bag in water to sift out the sand.' The last group had a different challenge altogether. They had to be creative by crafting make-shift poles to record marine organisms hiding behind coral crevices during the snorkelling session. In addition, good organisational skills were demonstrated by students. For example, in Group 1, they were tasked to study barnacle abundance at low tides. It meant tidal tables and good planning during the trip were crucial to complete the task. For example, this group had to manage their project work around low tides, which meant waking up at $4 \mathrm{am}$.

Indeed, HOTS fosters deep approaches to learning where Entwistle (1991) described that relating evidence to conclusions by reasoning and relating knowledge to experiences are forms of deep learning compared to surface learning, i.e., passively accepting ideas and routine memorisation of facts and procedures. Also, the learning agility to shift from one learning mode to another (i.e., learning-by-listening to learning-by-doing) in the learning cycle is important for effective experiential learning. When the student adapts and innovates to the demands of the learning situation, in this case, the field site, they learn to be problem solvers. Whilst the field trip allowed the demonstration of HOTS, it is unclear if these were new skills or students acquired beforehand, which is outside the scope of this paper. Nevertheless, it is clear from the qualitative video narratives that field trips are irreplaceable to laboratory practical wherein labs, students are learning in a protected and more constrained learning environment. Nevertheless, field trips enable experiential learning opportunities to use uncommonly utilised science processing skills, where a closed and controlled laboratory environment could not have replicated. These include designing field experiments, working within the limits of time and resources, adapting to unforeseen circumstances, including weather and tides, and the opportunity to witness for the first time unique marine ecosystems like the coral reefs.

In addition to cognitive skills, three other themes were identified, i.e., transferable skills (teamwork, ICT skill, e.g., proposal writing, video editing), values (environment awareness) and others (learning while having fun), which may be developed through the field trip. It is in line with past studies by Peasland et al. (2019), showing that when students have more control over their tasks, they develop a greater variety of transferable skills. Field experiences can provide a first-hand experience like the workplace environment by providing cognitive practice and improvement opportunities. In addition, effectively designed learning experiences that are student-centred student-driven with peer-to-peer interaction improve social skills (Rickinson, 2004), boosting confidence in working with peers and 


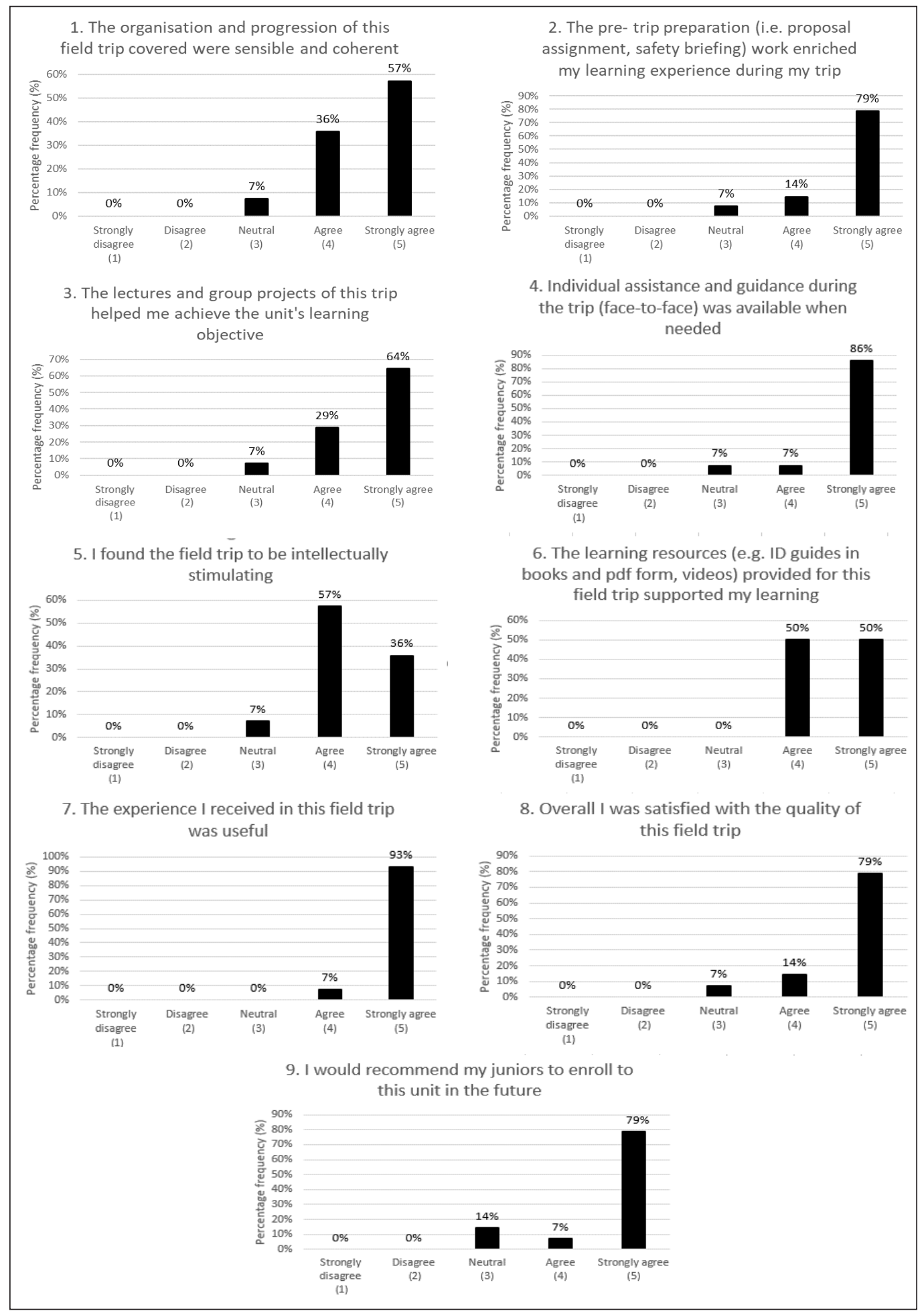

Figure 3. Student perception on field trip design 
developing skills transferable beyond the studied degree (Boyle et al., 2007). When students work collaboratively to share ideas and information, they can collectively bring up the standard of learning and knowledge. It could be in the form of picking up new and advanced ICT skills from each other that ultimately improves digital literacy. For example, video production skills, i.e., storyboarding, shooting, interviewing, transcribing, and editing, are used as they go along the learning sequence of their field project. Therefore, it is undeniable that experiential learning opportunities like these provide a collaborative platform for students to build HOTS skills, gain field experiences and further hone their collaborative skills to achieve a common goal. Ultimately, this can boost students' employability because to be employable in the twenty-first century, workers need to have skills, such as problem-solving and analytical, decision making, organisation and time management, risk-taking and effective communication (Robinson, 2006). Besides, a past study by Crompton and Sellar (1981) reported that fun outdoor education experiences could contribute to positive development in the affective domain. It was further supported by Boyle et al. (2007)'s findings that positive affective responses improve motivation, and consequently, students develop deeper approaches to learning and understanding. Also, Kuchel et al. (2015) discussed that field experiences could influence environmentally responsible attitudes and behaviours as students engage in a deeper understanding of the natural environment.
In other words, fun and engaging field trips positively affect motivation to approach learning on a deeper level, which could potentially manifest as one becoming more environmentally aware and responsible, as was the case for student D mentioning that "it was a memorable experience to witness the works of nature and the massive biodiversity of the coral reefs in Lang Tengah." He continued saying that "it makes him more determined to support marine conservation." It is especially heartening to see, but further validation work is needed to verify if positive affective responses from field trips can significantly influence environmentally responsible behaviours.

\section{Pre-Trip Activities Laid the Foundation for HOTS}

The quantitative analysis on students' perception of experiential learning opportunities showed that student perception was positive towards the pre-trip, duringtrip, and post-trip activities, respectively. It is aligned with qualitative analysis showing that the field trip design successfully provided experiential learning opportunities that enabled students to demonstrate all learning skills across Bloom's revised taxonomy. For example, more than $75 \%$ of respondents strongly agreed in the quantitative survey question no. 2 that "the pre-trip preparation work enriched my learning experience during my trip." Indeed, Panelli and Welch (2005) and Scott et al. (2012) supported that fieldwork training is necessary before increasing autonomy to allow students to use past experiences to 
inform future practice. From here, the pretrip activities, e.g., instructor-led fieldwork, is shown to be effective in equipping the students with the technical know-how before the field trip. This process is based upon "self-determination theory," where three governing criteria, i.e., autonomy, relatedness and competence, are needed to achieve optimal personal development (Deci \& Ryan, 2004). It is an interesting finding and worthy for future investigation, focusing on evaluating optimal levels of autonomy needed to facilitate the demonstration of an increased level of HOTS. Moreover, students felt that they were well supported during the field trip as reflected by more than $50 \%$ of respondents strongly agreeing for both survey question no. 4, "Individual assistance and guidance during the trip was available when needed" and survey question no. 6, "the learning resources provided for this field trip supported by learning." The level of support provided was shown to create a safe environment for students to be creative and confident in demonstrating HOTS when given the opportunities.

\section{Instructor Self-Reflection for Continuous Improvement}

This study began with a discussion of the field trip design to deliver experiential learning opportunities to students at a higher learning institution. After the unit was completed, the authors reviewed the introduced field trip design in terms of its bottlenecks and identified ways to improve further. First, in the following years, students will be shown videos made by the previous student cohort as part of the pre-trip activities. It will help new students understand the field trip expectations, especially on the field site's physical and geographical characteristics as well as limitations in terms of duration and equipment availabilities. Students can also identify past mistakes and challenges faced by their seniors and seek to improve from there. Secondly, students will be encouraged to complete a skills diary every night during the field trip. It is to aid them in reflecting on the learnings for that day, which would help them identify skills gained and learning gaps. Thirdly, a post-trip sharing session will be carried out. During the session, videos will be followed by a focus group discussion with instructor-guided questions. It can enable students to learn about the specific challenges encountered by other group members and how they overcame the problem together. It will allow students to build knowledge on the experiences and findings of other groups and stengthen student confidence as they share their findings and learning with the class. Finally, in terms of dealing with patchy internet connections on the island, it was noted that preparing a whiteboard with agenda details would enable students to keep track of program timings. Overall, by incorporating the points above, it is hoped that the field trip design becomes more refined with each successive improvement cycle for a better teaching and learning experience that facilitates HOTS. 


\section{STUDY LIMITATIONS}

This study has its caveats. Therefore, recommendations for future work are provided. The first caveat concerns the demonstration of HOTS in the current study using qualitative data extracted from the videos. In future work, it would be more convincing to conduct a pre-post survey to evaluate if HOTS were acquired before the study or during the field trip itself. Besides, student interviews and focus groups could help to understand further the relationship and influence of HOTS that encompasses deep learning elements like motivation, learner's intention and teacher influence (Marton et al., 1997).

Secondly, one of the study limitations was its small sample size limited to a learning unit at a university. Consequently, findings may not represent the population and can only serve as a general guide about the overall outcomes. It was inevitable because, as a third-year unit, university safety procedures limit a maximum of 20 people for any high-risk activities at any one time. One of the options to address this is for replicative studies to be conducted over the years to confirm the findings. Furthermore, the field trip design outlined in this study is suited for small classes and meets the learning needs of final year undergraduate students in which higher levels of cognitive thinking and transferable skills are critical to preparing them for the workplace. It is further recommended that due to the small sample size, face-to-face in-depth interviews with a few of the students would provide invaluable insights into their experiences and HOTS acquisition. From here, the field trip design in this study could be adapted for second years and pre-university education through a simplification exercise. Finally, this study recommends evaluating the effectiveness of formal (e.g., didactic lectures) and informal education (e.g., guest talk on conservation issues and field trips) and the long-term impacts on students' attitudes and behavioural changes in environmental awareness.

\section{CONCLUSIONS}

This study has described a purposeful field trip design to provide experiential learning opportunities to demonstrate HOTS in all three stages (pre, during, post) of the field trip. Indeed, field trips offer students valuable experiential learning opportunities to develop a wide range of cognitive skills, as revealed by the qualitative analysis. It is established here that the field trip design enables students to demonstrate learning skills across Bloom's taxonomy. In addition, study findings showed that students demonstrated a higher number of HOTS than basic thinking skills, further validating the assertion that purposefully designed field trips enable experiential learning opportunities that could not be reproducible in a closed environment like the laboratory setting. It was supported by a quantitative survey where the majority of respondents agreed that the pre-trip activities built an important foundation for students to demonstrate HOTS. In contrast, 
instructor self-reflection on the field trip design allowed continuous improvement year on year.

More than ever, the importance of purposeful field trip designs cannot be understated in a post-CoVID-19 pandemic world. With comprehensive risk assessment and management strategies, field trips should be continually emphasised and not be pressured to be removed as part of a cost-cutting exercise. Now is a window of opportunity to rethink, reframe and refine existing field trips. This work will serve a threefold impact by providing how an authentic experiential learning experience can be executed, an innovative teaching model for promoting higher-order thinking skills (HOTS), and a model of pedagogy reform for field trip designs. For a better teaching and learning experience that facilitates HOTS, future research could include collaborations with local NGOs to exchange and share new and related information.

\section{DECLARATION OF INTEREST STATEMENT}

The authors declare no conflict of interest.

\section{DATA AVAILABILITY STATEMENT}

The authors confirm that the data supporting the findings of this study, i.e., group project methodology and video transcription are available in the article's supplementary materials.

\section{ACKNOWLEDGEMENTS}

This work was supported by the Monash Education Excellence platform under the Education Excellence Teaching and Learning Grant (E/EE/LTG_07/2018/01); Tropical Medicine and Biology platform under the TMB grant (5140921-318-00); the Campus grant under the Sustainable Community Grant Scheme (SDG-2018-04$\mathrm{SCI})$ and the School of Science Education Seed Grant 2021 (SED-000076).

\section{REFERENCES}

Anderson, L. W., \& Krathwohl, D. R. (2001). A taxonomy for learning, teaching, and assessing: A revision of Bloom's taxonomy of educational objectives. Allyn \& Bacon.

Boyle, A., Maguire, S., Martin, A., Milsom, C., Nash, R., Rawlinson, S., Turner, A., Wurthmann, S., \& Conchie, S. (2007). Fieldwork is good: The student perception and the affective domain. Journal of Geography in Higher Education, 31(2), 299-317. https://doi. org/10.1080/03098260601063628

Crompton, J. L., \& Sellar, C. (1981). Do outdoor education experiences contribute to positive development in the affective domain? The Journal of Environmental Education, 12(4), 21-29. https://doi.org/10.1080/00958964.1981 .9942638

Dabamona, S. A., \& Cater, C. (2018). Understanding students' learning experience on a cultural school trip: Findings from Eastern Indonesia. Journal of Teaching in Travel \& Tourism, 1-18. https:// doi.org/10.1080/15313220.2018.1561349

Deci, E. L., \& Ryan, R. M. (2004). Handbook of selfdetermination research. University Rochester Press. 
Domin, D. S. (1999). A review of laboratory instruction styles. Journal of Chemical Education, 76(4), 543. https://doi.org/10.1021/ed076p543

Entwistle, N. J. (1991). Approaches to learning and perceptions of the learning environment: Introduction to the Special Issue. Higher Education, 22(3), 201-204. http://www.jstor.org/ stable/3447172

Essig, R. R., Troy, C. D., Jesiek, B. K., Buswell, N. T., \& Boyd, J. E. (2018). Assessment and characterization of writing exercises in core engineering textbooks. Journal of Professional Issues in Engineering Education and Practice, 144(4), 04018007. https://doi.org/10.1061/ (ASCE)EI.1943-5541.0000378

Ganapathy, M., Singh, M. K. M., Kaur, S., \& Kit, L. W. (2017). Promoting higher order thinking skills via teaching practices. $3 L$ : Language, Linguistics, Literature, 23(1), 75-85. http://doi. org/10.17576/3L-2017-2301-06

Heath, C., Hindmarsh, J., \& Luff, P. (2010). Video in qualitative research. Sage Publications.

Huisman, J., Kiviaho-Kallio, P., \& Lyon, D. (2019). Enhancing employability through experiential learning and reflective learning. In Conference Proceedings: The Future of Education International Conference. Filodiritto Editore. http://doi.org/10.26352/D627_2384-9509_2019

Hurley, M. M. (2006). Field trips as cognitive motivators for high level science learning. The American Biology Teacher, 68(6), 61-66. https://doi.org/10.1662/00027685(2006)68[61:FTACMF]2.0.CO;2

Jones, H. (2010). National Curriculum tests and the teaching of thinking skills at primary schools-parallel or paradox? International Journal of Primary, Elementary and Early Years Education, 38(1), 69-86. https://doi. org/10.1080/03004270903099785
Jose, S., Patrick, P. G., \& Moseley, C. (2017). Experiential learning theory: The importance of outdoor classrooms in environmental education. International Journal of Science Education, Part B, 7(3), 269-284. https://doi.org/10.1080/21548 455.2016.1272144

Kenayathulla, H. B., Ahmad, N. A., \& Idris, A. R. (2019). Gaps between competence and importance of employability skills: Evidence from Malaysia. Higher Education Evaluation and Development, 13(2), 97-112.

Kolb, A., \& Kolb, D. (2009). Experiential learning theory: A dynamic, holistic approach to management learning, education and development. In S. J. Armstrong, \& C. V. Fukami (Eds.), The SAGE handbook of management learning, education and development (pp. 4268). SAGE Publications Ltd. https://www.doi. org/10.4135/9780857021038.n3

Kuchel, L., Wilson, R. S., \& Ellis, W. H. (2015). Cameras, competition and creativity: Assessing 1 st year ecology in the field. International Journal of Innovation in Science and Mathematics Education, 23(2), 34-45.

Lei, S. A. (2010). Field trips in college biology and ecology courses: Revisiting benefits and drawbacks. Journal of Instructional Psychology, 37(1), 42-48.

Marton, F., Hounsell, D., \& Entwistle, N. J. (1997). The experience of learning: Implications for teaching and studying in higher education. Scottish Academic Press.

Mustaffa, R. (2007). Mengadaptasikan gaya pembelajaran pelajar ESL: Satu kajian kes pelajar tahun satu di UKM [Adapting ESL students' learning approach: A case study of first year students at UKM]. GEMA Online Journal of Language Studies, 7(1), 1-32. https:// https:// ejournal.ukm.my/gema/article/viewFile/185/158 
Nowell, L. S., Norris, J. M., White, D. E., \& Moules, N. J. (2017). Thematic analysis: Striving to meet the trustworthiness criteria. International Journal of Qualitative Methods, 16(1), 1-13 https://doi.org/10.1177/1609406917733847

Oliver, C., Leader, S., \& Kettridge, N. (2018). Birmingham Bog outdoor laboratory: Potentials and possibilities for embedding field-based teaching within the undergraduate classroom. Journal of Geography in Higher Education, 42(3), 442-459. https://doi.org/10.1080/030982 65.2018 .1455816

Orion, N. (1993). A model for the development and implementation of field trips as an integral part of the science curriculum. School Science and Mathematics, 93(6), 325-331. https://doi. org/10.1111/j.1949-8594.1993.tb12254.x

Panelli, R., \& Welch, R. V. (2005). Teaching research through field studies: A cumulative opportunity for teaching methodology to human geography undergraduates. Journal of Geography in Higher Education, 29(2), 255-277. https://doi. org/10.1080/03098260500130494

Passarelli, A. M. (2016). Using experiential learning theory to promote student learning and development in programs of education abroad (ORBH Working Paper 9/13/2011). Stylus Publishing. https://weatherhead.case. edu/departments/organizational-behavior/ workingPapers/WP-11-03.pdf

Peasland, E. L., Henri, D. C., Morrell, L. J., \& Scott, G. W. (2019). The influence of fieldwork design on student perceptions of skills development during field courses. International Journal of Science Education, 1-20. https://doi.org/10.108 0/09500693.2019.1679906

Rickinson, M. (2004). A review of research on outdoor learning. Field Studies Council, National foundation for educational research, United Kingdom, https://www.informalscience. org/sites/default/files/Review\%20 of\%20 research $\% 20$ on $\% 20$ outdoor\%201earning. pdf

Robinson, J. S. (2006). Graduates' and employers' perceptions of entry-level employability skills needed by Agriculture, Food and Natural Resources graduates $[\mathrm{PhD}$ thesis, University of Missouri]. https://doi.org/10.32469/10355/4328

Saldaña, J. (2015). The coding manual for qualitative researchers. Sage Publications Ltd. https:// www.sagepub.com/sites/default/files/upmbinaries/49731_Saldana_Chapter_1.pdf

Scarce, R. (1997). Field trips as short-term experiential education. Teaching Sociology, 25(3), 219-226. https://www.jstor.org/stable/1319398

Scott, G. W., Goulder, R., Wheeler, P., Scott, L. J., Tobin, M. L., \& Marsham, S. (2012). The value of fieldwork in life and environmental sciences in the context of higher education: A case study in learning about biodiversity. Journal of Science Education and Technology, 21(1), 11-21. https:// www.jstor.org/stable/41413281

Shafie, L. A., \& Nayan, S. (2010). Employability awareness among Malaysian undergraduates. International Journal of Business and Management, 5(8), 119-123. https://doi. org/10.5539/ijbm.v5n8p119

Sharlanova, V. (2004). Experiential learning. Trakia Journal of Sciences, 2(4), 36-39.

Wolfe, D. E., \& Byrne, E. T. (1975). Research on experiential learning: Enhancing the process. In Developments in Business Simulation and Experiential Learning: Proceedings of the Annual ABSEL Conference. Association for Business Simulation and Experiential Learning.

Zohar, A., Degani, A., \& Vaaknin, E. (2001). Teachers' beliefs about low-achieving students and higher order thinking. Teaching and Teacher Education, 17(4), 469-485. https://doi.org/10.1016/S0742051X(01)00007-5 


\section{APPENDICES}

\section{Appendix 1}

\section{Methodology of 4 group projects}

\section{GROUP 1: BARNACLES}

This experiment aimed to investigate the effects of disturbance on barnacle communities by comparing data from disturbed and undisturbed sites on Lang Tengah Island. The project objective was to better understand the impact of anthropogenic activities on barnacle communities. The findings of this study could contribute in the broader understanding of the role of disturbance in shaping barnacle communities in tropical waters and this can be further applied to mitigate the negative impacts of disturbance on barnacle communities. Three square quadrats of varying sizes, $1 \mathrm{~m}$ by $1 \mathrm{~m}$ (large), $0.75 \mathrm{~m}$ by $0.75 \mathrm{~m}$ (medium) and $0.5 \mathrm{~m}$ by $0.5 \mathrm{~m}$ (small) will be placed at each site; adopted method by Farrell (1989). The number of barnacles within the quadrat was be counted, however if the barnacle density were too numerous to count individually, percentage cover of barnacles in the quadrat was recorded instead. A size-wise comparison of the quadrats were made between both sampling sites. Reference sheets of common barnacle species were used to identify the species of barnacles on site, and pictures were for species unable to be identified immediately.

\section{GROUP 2: COASTAL MACROINVERTEBRATES}

This experiment aimed to compare the coastal macroinvertebrate species diversity between the disturbed site (high human traffic) and undisturbed site (low human traffic) on the Lang Tengah Island beaches to further evaluate the significance of human disturbances. The team was split into two groups where duplicates of disturbed and undisturbed sites were carried out simultaneously. A sand corer was inserted $30 \mathrm{~cm}$ into the sand and the area around the corer were cleared before removing the corer. The coring contents were immediately filtered using sieves of $1 \mathrm{~mm}$ pore size (Barba et al. 2010) into four buckets (Disturbed 1 and Disturbed 2; Undisturbed 1 and Undisturbed 2). The filtered samples were then categorised into morphology to aid in the quantification and identification processes.

\section{GROUP 3: MACROPLASTICS POLLUTION}

This project aimed to study macro-plastic abundance at varying sites on Lang Tengah's beaches, such as sites with varying public accessibility or sites of differing distance from the shoreline. The significance of this study were to raise student awareness of the impacts of human activities/behaviours on the marine and coastal ecosystems/habitats. In the long term, local community populations and tourists visiting the island could further their understanding of the importance of sustainable material usage by limiting their contribution to plastic pollution through personal actions such as; recycling, waste reduction and responsible purchasing. Four sites were chosen, two pristine, and two with high levels of human activity. At each site, students sampled along a $50 \mathrm{~m}$ transect line, constructing a $1 \mathrm{x} 1 \mathrm{~m}$ quadrat, sampling randomly every five metres within three metres of the transect line. A shovel and bucket were used to collect the top layer of sand to a depth of $10 \mathrm{~cm}$ to be filtered through a $5 \mathrm{~mm}$ pored sieve; the separated macroplastic were then transferred into a bucket ready for identification and weighing. Plastic composition were identified using visible recycling codes, while unidentifiable plastics were be categorized under other" and subdivided into hard and soft plastics.

\section{GROUP 4: MARINE FOOD WEB}

This project aimed to construct a concise marine food web specifically for the Lang Tengah Island. Various observational samplings were undertaken in order to establish the existing marine life present and then later identifying them to at least a genus level and analysing their species-specific interactions. Using the constructed food web, comparison of species presence/absence, species densities and abiotic factors in both pristine and disturbed ecosystems were done as well as to illustrate indirect interactions among species. 


\section{Appendix 2}

\section{Video transcription}

\section{GROUP 1: BARNACLE ABUNDANCE}

The major task of this group was the comparing of barnacle abundance between the disturbed and pristine sites on Lang Tengah Island.

According to the first speaker, she informed that due to heavy tourism they predicted that there will be less barnacle abundance at the disturbed site from the effects of human activities, thus it is presumed that she was able to apply some knowledge of what they have been taught already in class, as well as showed some values of environmental awareness.

Another student informed that on the first day, they went out as a group to different parts of the island to survey for their sites. This shows that the students were able to work in groups, thus applying teamwork/ collaborative skill to be able to successfully complete their project. The student further stated that they decided on their pristine and disturbed site based on the amount of people they observed throughout the day at the beach. From the video, it was obvious that the students were actually in a group (1 boy, and three girls), and they cooperatively worked together in critical thinking and applying how to achieve their goals, thus solving the problem at hand. Still on knowledge gained by the group, the student further informed that disturbed area has tourist stepping on the rocks to take pictures, snorkelers, etc.; while the pristine area was nearer toward the turtle bay where the tides are higher and less people were observed.

On the second day of their field trip, the student reported that: quadrates of $0.5 \mathrm{~m}$ was set on rocks in both pristine and disturbed site. This shows that the students of this group had knowledge about what they were to carry out in the field. Furthermore, 4 quadrates were placed at each site and they were divided into pairs to count the abundance by species. Here it is observed again that the students possessed group skills; Teamwork/ collaborative skill: which enabled them to successfully complete the project, and showed how each role was achieved. Each group counted the abundance according to various species.

Regarding the Problem solving/critical thinking skills by the students, it was observed as reported by the students that they encountered some problems. Thus, the students stated that: Some of the problems that they faced was that they had to go underwater to count the barnacles; besides that, there was an abundance of clams that has outcompete the barnacles which made it hard for them to observe the abundance of barnacles.

What then was the findings of this group? According to the one of the students, who reported, they found a total of 41 barnacles in the pristine site and 32 barnacles in the disturbed site. It was also reported that the results that they found was able to actually fit their proposed hypothesis where they predicted that they would find more abundance of barnacles in the pristine site compared to the disturbed site. Furthermore, this can be explained by heavy human activity surrounding their disturbed site, which was in front of the resort. Again here the students were able to exhibit some skills, specifically science process skills as well as higher order thinking skills, as they were able to explain reasons for the variances in the abundance of barnacles with regards to locations of the pristine site and the disturbed site. Furthermore, the students informed that they saw a lot of humans snorkelling around the area and also climbing on the rocks to take photos, among other activities. This shows that the students were very observant, which is one of the science process skills. They also stated that: this could have potentially affected the barnacle abundance in that area. Here it is seen that the students were able to apply higher thinking skills such as analysing, being creative in their assumptions, amongst others. Furthermore, the student also reported that the water in the disturbed area was also seen to be more polluted, and that in that area they saw a lot of plastic debris and in certain areas they also saw an oily sheen on the water, thus this could also contribute to the degradation of the barnacle community in the disturbed area. It was also discovered that barnacles found on a plastic bottle washed up the beach. All these shows that the students were critical in their analysis, and thus were able to combine application of their knowledge to what was seen in the field physically. 
Next was the new skills learnt by the students. As reported by one of the group members, he mentioned that for the new skills he learned or acquired from this project, firstly, he learnt how to find and also differentiate barnacles, because the barnacles they found were different from those found in other beaches he has gone to before. The student also stated that these barnacles were small in size, so basically they had to look very closely to find it, and also the amount of the barnacles was small (like around $0.6 \mathrm{~cm}$ ). He also stated that he learnt how to differentiate barnacles according to their colour and sizes, the colours of the barnacles here is white and black with stripes. The second new skills learnt by the student was: how to undergo quadrat sampling using the rope. According to the student, sometimes during their quadrat sampling, the rope submerged in the water, thus making them to count the barnacles in the quadrat under water. He stated that sometimes, he had to dive his head into the water. Here, it is observed that the student also possessed some critical thinking skills combined with problem solving skills, going extra mile to achieve the goal of the experiment.

The next part is regarding the benefits of this study to the students. One of the group members reported that one of the benefits of the study is the increase of awareness on the importance of barnacles to the ocean (AWARE OF IMPORTANCE OF SUSTAINABILITY). She further stated that this is so because barnacles are largely overlooked and their role to the ecosystem is not really recognized, especially in countries such as Malaysia. Thus, they hoped that as a result of conducting this study, they (group members) can increase the awareness on the importance of barnacles on Lang Tengah Island to the local community (ENVIRONMENTAL AWARENESS). From here, it could be noticed that the student answering this question was having fun, sitting on a moving bench on the beach, however, this didn't distract the student from giving great insights to questions being asked. Still on the benefits, the student stated that another benefit of the study is that the results being found by their group can help in improving the understanding of the effects of human disturbance on barnacle communities so that in the future, these effects can potentially be migrated.

Another student took it up from there, and summed it up stating thus: that their disturbed site has less barnacle abundance than their pristine site due to the effect of human activities such as snorkelling, tramping and water pollution. She also stated that they were able to identify 2 distinct barnacle species which were present at both sites. She further stated that they were able to overcome all the problems faced as a group together. Again, this indicates that the group members were able to exhibit their problem solving/critical thinking skills to eventually achieve their goals of the project.

However, the student mentioned that although the experiment can be concluded as successful, yet there is a lot of room for improvements. This shows that the students had quite a great knowledge of the field project, to the extent of even identifying and proposing other rooms for improvements.

So the next section discusses the improvements that could be made from the experiment, as reported by the students. One of the students, while having fun on the beach, reported thus: that after conducting their experiment, the improvements found could be made to the methods being used, such as placing a rope anchored with something heavy down to the bottom of the water to allow barnacles to colonize the rope (The student actually demonstrated the improvement being suggested by placing the rope into the water). This could indicate how the student was able to learn while having fun, as well as being able to apply critical knowledge in a practical way, also it could be stated that the student also had higher thinking skills, to have being able to come up with such improvement ideas. Furthermore, the student stated that with the new method, after three months, the investigators can them come back and investigate the barnacle species and abundance on the rope.

As reported by another student, due to the time constraints of their experiment, they actually couldn't conduct the rope method because three months is needed; however they stated that they would try using a belt transect; where they would lay about a 10 meter line and use a 1 meter pole and go along the 10 meter transect and thus everything that falls within the 1 meter line would be counted as their data. The student further gave an example stating that; for example, they would count everything that falls within this line (as described in the video) and go along the transect as follows. 
The students were able to apply a lot of knowledge regarding their experiment topic, and worked together as a group to achieve their expected outcome.

\section{GROUP 2: CORAL ABUNDANCE}

The major task of this group was to identify the description of coral species in relation with the distance of the collection site from the sea on Lang Tengah Island.

The students started by presenting the materials that were used which are: PVC pipes, sieves, buckets, coral, and shovel. The students reported that the first sampling site has an elevation of $9 M$, the second sampling site has an elevation of $7 M$, and the third sampling site has an elevation of $5 M$. It is discovered that this group exhibited a good science process skills, most especially in classifying and measuring via the use of numbers, as stated above. Also, it was discovered that the group possessed a team-like/collaborative skill, as it was seen that they worked together in group, while carrying the coral net. At an instance, a student was found reading the GPS location thus exhibiting some information technology skill, while other group members were performing other respective duties, some observing, some fixing the pipes in appropriate places, thus having a strong collaborative power to achieve their goal. At the point of searching for the corals, it was obvious that the students possessed another skill of carefully identifying the corals from the sand. They carefully picked out the corals from the sand and put into a separate container.

The team were not left of problems, however they were able to adapt to the problem they faced, thus indicating that they possessed the problem solving/critical thinking skills. The problem faced as reported by the students was the inability to use the coral sampling tool as the sand was too dense, thus they had to make use of their hands to pick up the corals on the surface that were bigger than $5 \mathrm{~cm}$. Lastly, they separated the corals based on their morphology.... The also stated the importance of corals, that they are essential as they provide shelter for many royal organisms and they also protect from damaging infections. This shows that the students had great knowledge about their project, and also had some higher order critical thinking skills. The students also stated that their findings can be used as a baseline study for future studies who wish to further investigate on the coral biodiversity of Lang Tengah. Another skill of evaluation and analysing was applied as the students after the whole experiment still measured the corals via the use of barometers to reconfirm the measurements so as not to miss anything out. Here, it can also be noted that they possessed science process skills. After categorizing the corals according to species, they weighed the corals of each sizes so that a representation of species abundance can be obtained. It can also be discovered that the students exhibited some higher order thinking skills, as they weighed each coral according to their sizes, for purpose of obtaining representation of the abundance of each species.

The findings from this group, as they were more into identifying species of corals is given thus. The coral species found by the group are: Isopora, Montastrea, Acropora, Pavona, Seriatopora, Pocillopora, Porites, Turbinaria, and Psammocora.

For the discussion segment, a question was raised as to: Why they observed more dead coral species at site 3 ? The answers were provided thus: Water from the high tide .... washes out and only reaches a certain elevation, and based on that reason, the high tide....does not go pass collection site 3, but at a higher elevation, they were still able to observe exclusive species like: Turbinaria species with elevation of 9M, Montastrea species with elevation of 7M. Furthermore, this could be due to the occurrence of the Monso season where tides are higher, therefore new day coral species could be washed out for the inland. Perhaps this explains it was able to still observe new species in collection site 1 and 2. Apart from the species of the corals observed, another parameters that was measured in this experiment is the weight of the corals as representatives of the species abundance. Their results suggested that Acropora species is the most abundant coral species observed as it was present in all sites and had the heaviest weight across the three sites. This information suggests that the students were able to make inferences with regards to their findings from the experiment. 
In conclusion, the gaps identified by the group was the proper knowledge of coral diversities with regards to the morphology of corals in Lang Tengah Highland. Also, the students stated that it was difficult to identify the coral species (space?) morphology alone even after using the coral enabler. Therefore for future references, the students recommend the study of live corals instead of dead ones, of course with the help of guide tips, so that a better representation of the coral diversity in Lang Tengah can be obtained.

At the end of the video, there were clips showing the group members having more funny adventures and being able to have fun even while learning.

\section{GROUP 3: LANG TENGAH PLASTIC PROJECT}

This group project involved Mesoplastic pollution in Lang Tengah, with the aim of studying the effect of the hotel presence on the plastic pollution on the beach. Their research question is: How does the presence of hotels impact the amount of mesoplastic on a beach?

Mesoplastic pollution is an ecological hazard on tourist islands like Lang Tengah.

The research methodology as chosen by the students was to select sites with and without hotels. This shows the creative higher order thinking skills of the students.

The students were able to work as a team, in a collaborative manner, as they helped each other achieve their goal, like measuring the transect at each site together, holding the measurement ropes, etc.

At each site, measure a $50 \mathrm{~m}$ transect parallel to the shore; throw a quadrat haphazardly every 10 metres. The students also excavated the top $5 \mathrm{~cm}$ of sand from the quadrat (This again was done in group, by two girls, thus showing the collaborative/team spirit.

Furthermore, they sift out plastic and coral using a $5 \mathrm{~mm}$ sieve. At this point, they noticed that the process was too slow and thus, this posed as a challenge and problem in their research progress. To be able to solve this problem, they exhibited a creative higher order thinking skills, and problem solving skills by instead filling up a mesh bag with the quadrat sand which definitely hastened up the process and also produce better result.

Further, they immersed the bag in the water to sift out the sand, which according to them was much faster. Next, they sift through coral fragments to find plastic. This shows the analysing skills of the students, and their evaluation skills in finding plastics. They bag plastic pieces according to quadrat, Here, some science process skills were exhibited by the students, most especially in classifying and measuring via numbers and dimensions, as regarding the use of quadrats. The next step was to weigh each bag analytical scales; here the students manifested the information and communication technology skills, as they were able to make use of the technology in the lab to perform their analysis.

This section provides the results from their project. The results show that litter in Site 1 was composed offar smaller plastics that that of Site 2. Also, Litter was mainly composed of plastic drink bottles, nylon and straws. It was also discovered that the average weight of plastic found at Site two is almost seven times more than site 2 , implying that it was significantly higher than Site one. They were also able to apply some scientific process skills, as they stated that the standard variation shows that site 2 has higher variation of plastic found in each quadrant, thus the amount of plastic found in each quadrat has more variableness at site 2.

The students in this group further went ahead to find out the reasons for their results, thus this implies that they exhibited higher thinking order skills, as well as utilized information and communication technology skills to sieve more information from their experiment sites, to be able to make inferences. In regards to this, they conducted a short interview with the hotel staff and it revealed that Site 1 is being cleaned daily by the hotel staff, while Site 2 is being cleaned on occasional basis by the Turtle Watch volunteers. In addition to 
that, it was also discovered that the island's recycling is piled right behind Site 2 for pickup, and can spread easily onto the beach.

They went further to find out and explain how their data can be used. Here it can be discovered that the students exhibited some inference making skills, enabling them to make valuable contributions from their study. Thus, they stated that the data can be used to encourage hotels to implement or expand cleaning programs. Also, the litter composition enables them to determine an approximate source; for the tourists (bottles + wrappers), and for the fishing boats (nylon rope).

Further, a question as to how these findings could benefit the society was discussed, thus showing that the students had acquired vast knowledge from their project and were able to apply it even for future benefits. Thus, it was stated that improving waste management on tourist islands will benefit hotel staff by bringing in more "eco-tourists", hence providing an economic incentive. Also, removing the risk of mesoplastic pollution from tourist islands will reduce plastic bioaccumulation and injury in wildlife.

Next was the gaps that were identified by the students in their study. Firstly, they weren't able to identify the exact source of the plastic (island/mainland) or the manufacturer. Secondly, there is no research on how plastic is affecting the marine or terrestrial biodiversity on Lang Tengah (even though the Turtle Watch have useful observations). Thirdly, it wasn't possible to identify the type of plastic or the manufacturer in most cases.

They also made some recommendations for future projects, thus exhibiting inference skills (science process skills). They stated that Firstly, in order to improve their study in the future, rather than digging, it is better to only collect plastic from the surface so that transects can be longer and quadrats can be more frequent. Second recommendation is to run a transect perpendicular to the shore to better understand patterns of litter disposal: so as to find out if it is coming from the land or the sea? Thirdly is to compare more sites and pair transects with a biodiversity survey to check for any associations.

\section{GROUP 4: LANG TENGAH FOOD WEB}

Some information from the introductory part: Coral reefs are large underwater structures composed of clusters of coral polyps held together by calcium carbonate. It harbours the most diverse underwater ecosystem in the world. In fact, coral reefs support $25 \%$ of all marine life despite only occupying about $1 \%$ of the ocean's area. Coral reefs actually provide one of the basic needs for all the reef fishes, which is actually shelter. By supporting a wide range of plants and animals, reefs play an important role in maintaining a balanced relationship between predators, prey and organisms in competition for the same resources. They also provide hundreds of millions of people with essential food provisions, livelihoods, flood protection and crucial economic opportunities. Malaysia houses approximately 4000 square kilometres of coral reefs and is part of the Coral Triangle, making it an important hotspot for marine ecosystem. However, the reefs of Malaysia are significantly understudied and this study sets out to understand the marine ecosystems of Lang Tengah and to address the knowledge gaps. The students proved that they had adequate background knowledge about their project; this is perhaps based on what they have studied in class before coming to the field.

The students were found having fun on the beach cruise, and this indicates that they were learning and having fun at the same time, thus balancing the whole process.

As reported by one of the students, Food chains are sequential networks that show how energy is transferred from one trophic level to another, when several are combined together, then you get a food web. Each life inhabiting this unique and delicate ecosystem are all interconnected and each interactions can be represented by a food web. They further indicated that their project site is Lang Tengah, a small island situated off coast of Kuala Terengganu and sandwiched between Perhentian and Redang island. Further, it was noted that it is also a popular spot for hundreds of green sea turtles to lay their eggs on the island's white sand beach. 
Reports were also made regarding the site collection. For the site selection, the students reported that they had 5 different snorkelling sites to conduct their observational sampling. They also informed that the data obtained will be used to construct a comprehensive and representative food web of Lang Tengah. The five sites are selected in such a way that it consists of pristine and disturbed area. How they defined the status of a snorkelling site is based on human activities, human inhabitant (showing that they possessed values of environmental awareness, and were aware of the importance of sustainability), infrastructure such as jetty and condition of the coral.

Further is the data gathering process. They stated that to gather data for their food web, they conducted an observational sampling at areas with varying degree of disturbance. This shows that the exhibited some science process skills, such as observation and analysis skills. With underwater cameras, they snorkel at the selected sites and record the aquatic flora and fauna present at each site (this showed that they also exhibited some information and communication technology skills, as well as were able to apply some higher order thinking skills to achieve their goal). Also, they made use of clever little improvisations, such as DIY extension to improve the quality of pictures/videos taken for later identification. Again this shows that they had problem solving/critical thinking skills, as they were able to think critically and come up with better improvisations to carry out their work, thus troubleshooting problems on hand. They informed that the good thing about conducting an observational study is that it is cost-effective and has relatively low impact to the environment. (Again, they possessed values such as environmental awareness and knew the importance of sustainability to environment). After the identification stage, they constructed the food web using Adobe Photoshop and Adobe Illustrator (This showed that the students had skills of information and communication technology, which helped them to be able to make use of the technology tools in constructing their food web).

They were also able to classify and make representations of each elements. Each node represents a marine organism and their prey-predator relationship is depicted by a line. Food webs can be used to visualize the transfer of energy up various trophic levels. This helps in providing important insights into the effects and extent of pollution on the marine ecosystem and the mechanics of bioaccumulation. Besides that, it serves as a foundation for further research opportunities.

Here, the students showed that they exhibited science process skills, thus being able to make inference from their findings. They stated that through their findings for the past few days on the field, they studied that at the bottom of the food web, there exists the autotrophs, which are the primary producers such as corals and algae. Also, they discovered that there are primary consumers, of which most of them are herbivores, such as parrotfishes and sea urchins that feed on corals. Further, there are many sea cucumbers that feed on the algae. Going along the food web, they observed and saw many secondary producers; these are the reef fishes which they noticed were in abundance. This can be the damselfishes, butterfly fishes and so on. They feed on shrimp, plankton and other small marine invertebrates. Finally, there are the tertiary consumers, these are typically carnivores which feed on other fishes like the barracudas and black tip reef sharks. The food web can be interconnected as each species affects the population of other species, thus it is important to maintain the health and biodiversity of the coral reefs.

They further suggested improvements to be made for their study, and is stated thus. One of the improvements for their study is that there should be more snorkelling sites; also there is need for more data to be able to achieve a conclusive result. Another menial tweak is to approach the marine fishes closer by diving. This is so that it would be possible to further observe coral reefs at the bottom that are too deep from the surface.

Furthermore, though it may seem insignificant, studying food webs provide fundamental knowledge of an ecosystem which stems into many different fields. One of the group members mentioned that the field trip made him realize the aforementioned, and he also believed that everyone can agree that they all bonded up together as a team, thus exhibiting team/collaborative skills. 
Another team member stated that reading papers and watching plenty of documentaries will never out win seeing the coral reefs with his own eyes, thus, they were glad to have had the opportunity of the field trip and being able to learn new things. They also reported that it was a memorable experience, to witness the works of nature (having fun) and the massive biodiversity of the coral reefs in Lang Tengah. The team member also stated that it makes him more determined to support marine conservation.

Another team member also reported and expressed his joy that: the experience was an unforgettable one, and he has learnt so much from the trip (had fun and learnt new things). He further stated that, he also learnt how to cooperate well with the team and that it also helped in providing basic skills to write a scientific proposal (acquired scientific process skills) and carry out the field experiment. He further stated that he was very grateful for this opportunity that the unit offers, stating that the experience will prove to be useful for the future.

The ending clips also showed that the students had a lot of fun during the field trip.

\section{GEOLOGICAL INFORMATION}

The geological coordinate of the field site is $5.7960^{\circ} \mathrm{N}, 102.8961^{\circ} \mathrm{E}$. The island is located about $40 \mathrm{~km}$ north east of Kuala Terengganu (22.5 km from Tanjung Merang) on the east coast of peninsular Malaysia. 